\title{
Post ablation timing to best visualize left-atrial Llesions: a feasibility study
}

Ibrahim Saeed ${ }^{2,3^{*}}$, Joseph S Soltys ${ }^{1}$, Sanjaya Gupta ${ }^{2,3}$, Ryan Longmore $^{3}$

From 19th Annual SCMR Scientific Sessions

Los Angeles, CA, USA. 27-30 January 2016

\section{Background}

Catheter-based atrial fibrillation (AF) therapy often uses cryo-balloon ablation of pulmonary vein (PV) ostia to achieve rhythm control. Prior studies suggest the ability of late gadolinium enhancement cardiac MRI (LGE-MRI) to visualize radiofrequency-induced scar. The optimal time after therapy to visualize cryo-ablation lesions is unknown. This study evaluates the relationship between the time of LGE-MRI acquisition after ablation and visualization of cryoballoon-induced scar.

\section{Methods}

Eleven consecutive patients ( $9 \mathrm{M}$, age $61 \pm 6 \mathrm{y})$ undergoing cryoablation for AF were prospectively enrolled. All patients had pre-procedural left atrial angiography with LGE-MRI (1.5T Signa HDx, General Electric, ) to define left atrial and pulmonary vein (PV) anatomy. All patients underwent repeat LGE-MRI between 7-28 days postablation. Images were visually assessed for scar (estimated as percent circumferential enhancement) detected in the PV antrum and placed in quartiles of definite LGE, likely LGE, unlikely LGE, and no LGE.

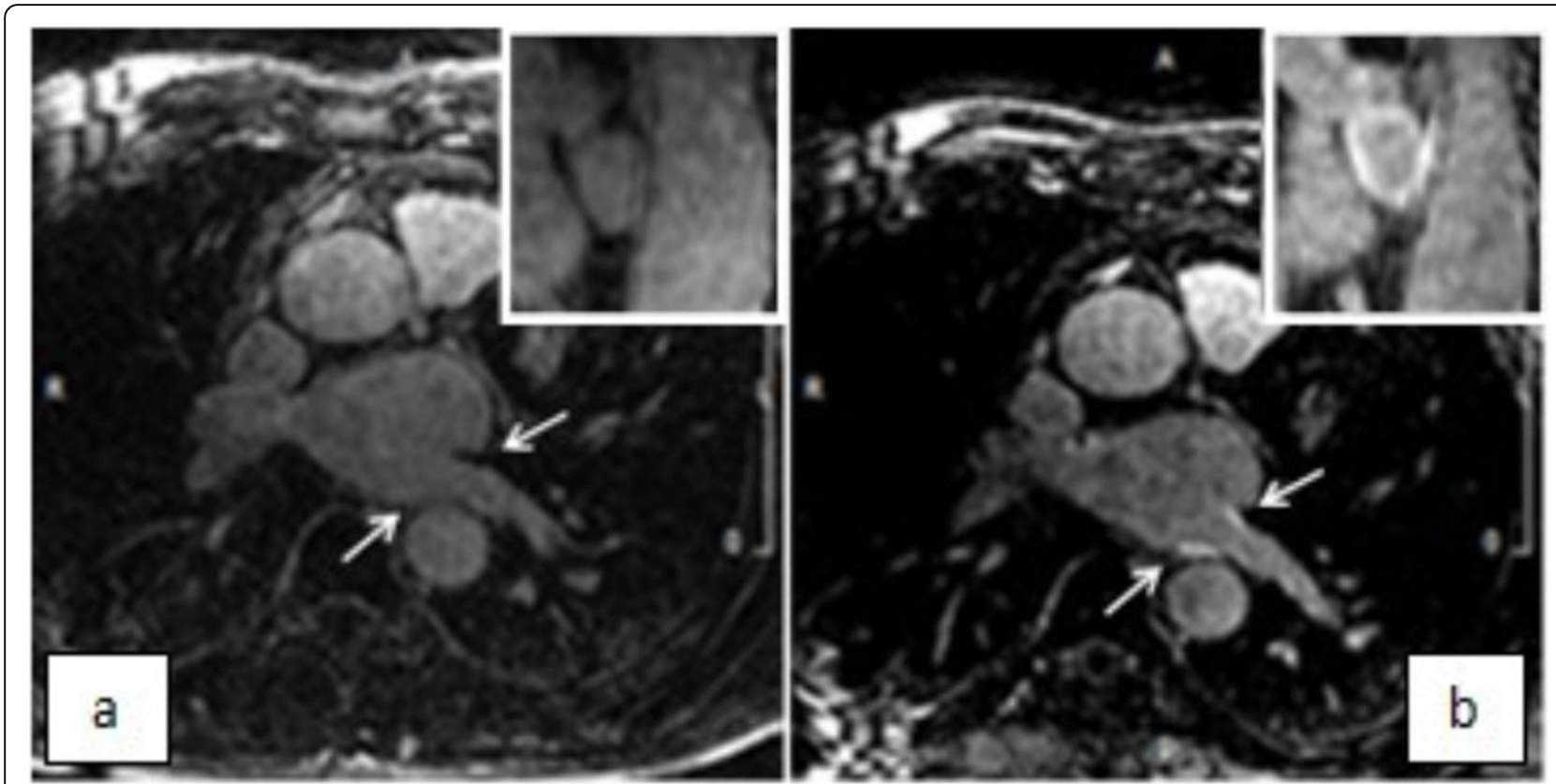

Figure 1 Typical acquisition showing pre ablation (a) and 20 days post ablation (b) LGE.

${ }^{2}$ Saint Luke's Mid America Heart Institute Cardiovascular Consultants, Kansas

City, MO, USA

Full list of author information is available at the end of the article 


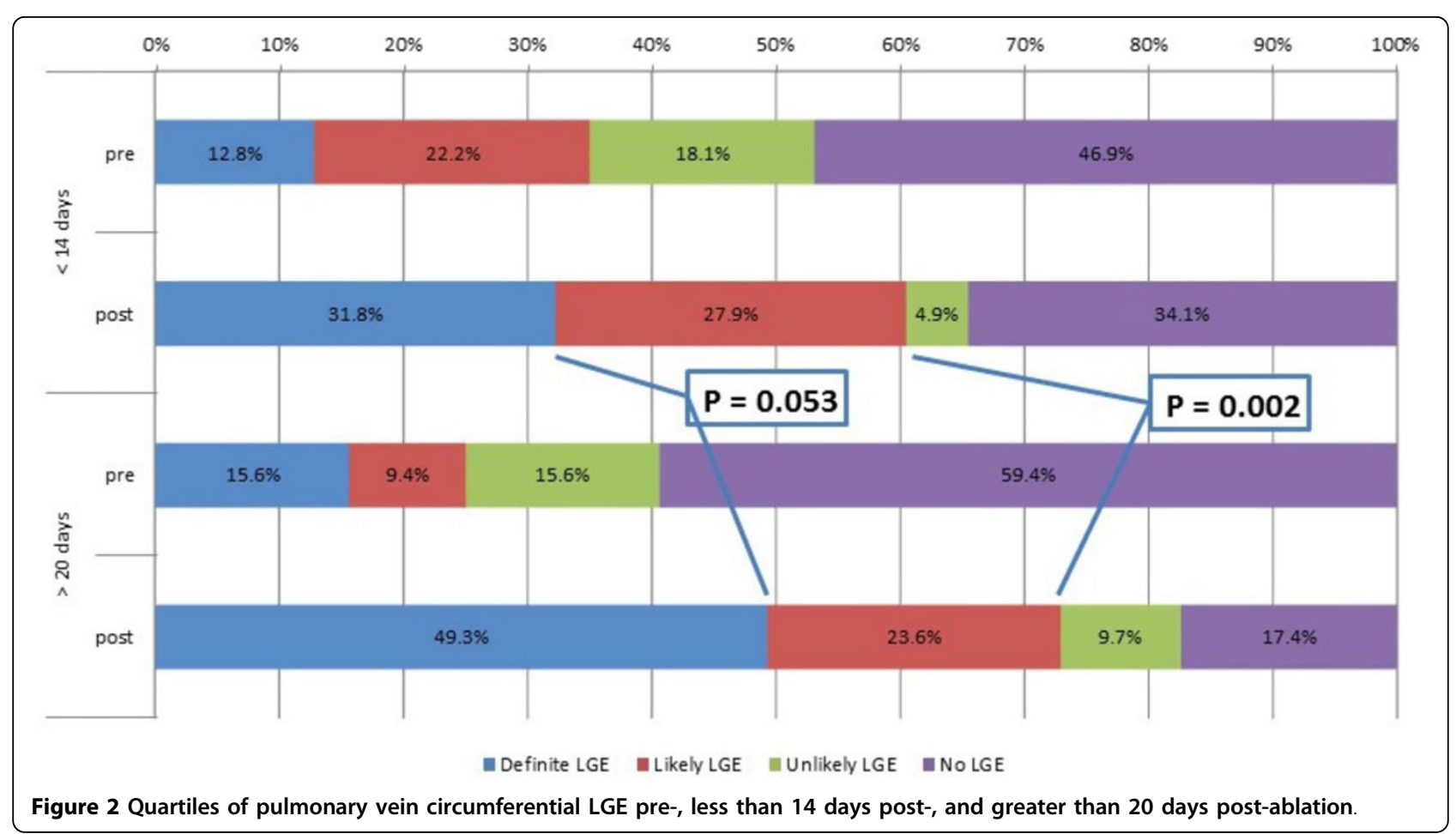

\section{Results}

44 PVs were assessed both pre- and post-procedure, and all but 6 pre-procedural were characterizable. At $<14$ days post-procedure, there was $31.8 \%$ definitely LGE circumferentially vs. $49.3 \%$ LGE > 20 days $(\mathrm{p}=0.053)$; and a combined definite and likely LGE of $59.7 \%$ circumferential LGE vs $72.9 \%>20$ days $(\mathrm{p}=0.002)$, despite achieving electrical PV isolation in all 44 patients.

\section{Conclusions}

This study demonstrates the feasibility of observing cryoablation induced PV scar on LGE-MRI by delaying imaging until 20 days post-ablation.

\section{Authors' details}

${ }^{1}$ Cardiovascular Imaging Technologies, Kansas City, MO, USA. ${ }^{2}$ Saint Luke's Mid America Heart Institute Cardiovascular Consultants, Kansas City, MO, USA. ${ }^{3}$ University of Missouri - Kansas City, Kansas City, MO, USA.

Published: 27 January 2016

doi:10.1186/1532-429X-18-S1-P203

Cite this article as: Saeed et al:: Post ablation timing to best visualize left-atrial Llesions: a feasibility study. Journal of Cardiovascular Magnetic Resonance 2016 18(Suppl 1):P203.

\section{Submit your next manuscript to BioMed Central} and take full advantage of:

- Convenient online submission

- Thorough peer review

- No space constraints or color figure charges

- Immediate publication on acceptance

- Inclusion in PubMed, CAS, Scopus and Google Scholar

- Research which is freely available for redistribution 